\title{
In vitro effects of glycyrrhetinic acid and hyaluronic acid on the growth of vulvovaginal Candida albicans and other yeasts
}

\author{
Martina Stevan, ${ }^{1}$ Eleonora Fusato, ${ }_{1}^{1}$ Decio Armanini, ${ }^{2}$ Giulio Bertoloni, ${ }^{3}$ Francesco De Seta, ${ }^{4}$ \\ Christian Leli, ${ }^{5}$ Mario Rassu ${ }^{1}$
}

${ }^{1}$ U.O.C. Microbiology and Virology, S. Bortolo Hospital, Vicenza; ${ }^{2}$ Department of Medical and Surgical Sciences, University of Padua, Padua; ${ }^{3}$ Department of Molecular Medicine, Padua; ${ }^{4}$ Department of Obstetrics and Gynecology, IRCCS Burlo Garofolo, University of Trieste; ${ }^{5}$ Department of Experimental Medicine, Microbiology Section, University of Perugia, Italy

\section{Summary}

Aims. The present study aimed to test the in vitro activity against Candida albicans and non-albicans strains of $18-\beta$ glycyrrhetinic acid (18- $\beta$ GA) and hyaluronic acid (HA), both alone and in combination. This antimicrobial activity was assessed using the National Committee for Clinical Laboratory Standards (NCCLS) method on Candida strains that were isolated from patients with recurrent vulvovaginal candidiasis (RVVC).

Results. Our results demonstrate that the anti-Candida activity is independent from antifungal susceptibility level and the fact that the growth inhibition is stronger at acidic $\mathrm{pH}$ level makes the two drugs a promising biological alternative for the topical treatment of vulvovaginal candidiasis (VVC) and RVVC.

Correspondence: Mario Rassu, U.O.C. Microbiology and Virology, S.Bortolo Hospital, viale Rodolfi 37, Vicenza, Italy.

Tel.: +39.0444.927912.

E-mail: mario.rassu@aulss8.veneto.it

Key words: $18-\beta$ glycyrrhetinic acid; hyaluronic acid, Candida albicans; Candida non-albicans; recurrent vulvovaginal candidiasis.

Acknowledgements: We are grateful Dr. Bryan Larsen for his critical review and revision of the English language in this manuscript.

Contributions: the authors contributed equally.

Conflict of interest: the authors declare no potential conflict of interest.

Received for publication: 2 August 2017.

Revision received: 13 October 2017.

Accepted for publication: 13 October 2017.

(C) Copyright M. Stevan et al., 2017

Licensee PAGEPress, Italy

Microbiologia Medica 2017; 32:6974

doi:10.4081/mm.2017.6974

This article is distributed under the terms of the Creative Commons Attribution Noncommercial License (by-nc 4.0) which permits any noncommercial use, distribution, and reproduction in any medium, provided the original author(s) and source are credited.
Conclusions. Furthermore, the reduction of both budding cells formation and germ tube elongation, on mammalian cell monolayers, may explain the observed growth inhibition and suggest a decreased virulence, respectively.

\section{Introduction}

Mucocutaneous candidiasis can be divided into nongenital disease and genitourinary disease (1). Clinical manifestations of genitourinary candidiasis are mainly represented by vulvovaginal candidiasis (VVC) in women, balanitis and balanoposthitis in men, and candiduria in both sexes (1). Among the many causes of vaginitis, VVC is the second most common after bacterial vaginosis and more than $40 \%$ are diagnosed in primary care settings (2). A recent survey conducted in five European countries and in the United States reported a prevalence of VVC between $29 \%$ and $49 \%$, and a prevalence of recurring VVC (RVVC, defined as a $12-$ month period with 4 or more infections) of $9 \%$ (25). Among Candida spp. recovered from vaginal swabs, Candida albicans is the most common $(1,12)$, nevertheless Candida non-albicans have increasingly been identified as the cause of vulvovaginitis, differing considerably with regard to virulence and antimycotic drug susceptibility (12). Indeed, treatment for Candida glabrata or Candida krusei VVC is generally unsuccessful with typical vaginal and oral drugs, and alternative treatments have been proposed, such as boric acid, amphotericin B, and echinocandins, but nevertheless, failures are becoming more common (16). Therefore, there is the need for new therapeutic strategies against non-albicans VVC, exhibiting distinct mechanisms of action and/or evasion of resistance $(6,20)$.

Glycyrrhizin, a compound derived from Glycyrrhiza glabra, and its hydrolytic derivative $18-\beta$ glycyrrhetinic acid (18- $\beta$ GA) have been shown to possess antiviral and antimicrobial activity $(7$, $9,13,15,17)$, and it has also been reported an in vitro activity against $C$. albicans strains (19). Similarly, hyaluronic acid (HA) too has been described as having a fungistatic activity in some studies $(11,23)$, and $C$. glabrata and $C$. parapsilopsis, in particular, displayed a HA dose-dependent growth inhibition (3).

The aim of the study was to investigate the antifungal susceptibility of $C$. albicans and non-albicans strains isolated from RVVC patients, and the activity of $18-\beta \mathrm{GA}$ and HA, both alone and in combination, against the same strains, in the light of a possible future use of these molecules for the treatment of mucocutaneous candidiasis. 


\section{Materials and Methods}

\section{Candida yeast isolates}

Seven C. albicans and 24 non-albicans strains (13 C. glabrata, 6 Saccharomyces cerevisiae, 2 C. krusei, 1 Candida guilliermondii, 1 Candida lusitaniae and 1 Zygosaccharomyces spp.) isolated from vaginal exudates of women suffering from RVVC were included in the study. The isolates were cultured on Sabouraud agar with Chloramphenicol (DIFCO USA), and identified by the API 20C system (bioMerieux, Marcy-l'Etoile, France). The antifungal susceptibility testing of the non-albicans and non-Candida strains was performed, against (amphotericin, fluconazole, itraconazole, ketoconazole, 5-fluorocytosine and voriconazole), with Sensititre Yeast One panels (Trek Diagnostic Systems, UK), and interpretation of results was performed using Clinical Laboratory Standards Institute (CLSI) guidelines.

\section{Measurement of non-albicans and non-Candida growth rate in the presence of $18-\beta G A$}

18 - $\beta$ GA was dissolved in ethanol to a final concentration of 10 $\mathrm{mg} \mathrm{mL} \mathrm{m}^{-1}$ (stock solution) and stored at $4^{\circ} \mathrm{C}$. Doubling dilutions of 18 - $\beta$ GA ranging from $100 \mu \mathrm{g} \mathrm{mL}{ }^{-1}$ to $0.09 \mu \mathrm{g} \mathrm{mL}^{-1}$ were prepared in RPMI 1640 broth (Sigma, St. Louis, Mo.) containing L-glutamine $0.3 \%(\mathrm{w} / \mathrm{v})$ and glucose $2 \%(\mathrm{w} / \mathrm{v})$, buffered with 3 -(n-morpholino) propanesulfonic acid (MOPS) $0.165 \mathrm{M}$, at different $\mathrm{pH}$ (ranging from 4.0 to 7.0) in 96-well microtiter plates according to the National Committee for Clinical Laboratory Standards (18). After adding the inoculum, the plates were incubated at $35^{\circ} \mathrm{C}$ and the absorbance was determined spectrophotometrically at $620 \mathrm{~nm}$ $\left(\mathrm{OD}_{620}\right)$ after $0,2,21,24$ and $48 \mathrm{~h}$ of incubation, using a GENios plate-reader (Tecan) and Magellan version 4.0 software. An inoculum with a concentration of $1-2.5 \times 10^{3}$ cells $\mathrm{mL}^{-1}$ was standardized spectrophotometrically and validated by quantitative plate counts. All analyses were conducted in duplicate and, for each strain, values were given as the mean of three measurements.

\section{Measurement of Candida albicans growth rate in the presence of 18- $\beta$ GA and/or HA}

18- $\beta$ GA stock solution and HA dissolved in RPMI 1640 broth and were added to the 96 well microtiter plates to obtain the following final concentrations: $18-\beta \mathrm{GA} 0.01 \%(\mathrm{w} / \mathrm{v}), 18-\beta \mathrm{GA} 0.02 \%$ $(\mathrm{w} / \mathrm{v})$, HA $0.2 \%$ (w/v), HA $0.4 \%(\mathrm{w} / \mathrm{v}), 18-\beta \mathrm{GA} 0.01 \%(\mathrm{w} / \mathrm{v})+\mathrm{HA}$ $0.2 \%(\mathrm{w} / \mathrm{v}), 18-\beta \mathrm{GA} 0.02 \%(\mathrm{w} / \mathrm{v})+$ HA $0.4 \%(\mathrm{w} / \mathrm{v})$. Candida albicans cells were inoculated in every well at a concentration of 1$2.5 \times 10^{3}$ cells $\mathrm{mL}^{-1}$ for a final volume of $200 \mu \mathrm{L}$. The plates were incubated at $35^{\circ} \mathrm{C}$ and the $\mathrm{OD}_{620}$ was read after 0,24 and 48 hours, using GENios plate-reader (Tecan) and Magellan version 4.0 soft- ware. All analyses were performed in duplicate and, for each strain, values were given as the mean of three measurements. Aliquots from broth cultures in RPMI 1640 broth, set up in the same experimental conditions, were collected at 0,24 and $48 \mathrm{~h}$ of incubation, and were used for: i) determination of colony forming units (cfu $\mathrm{mL}^{-1}$ ) by plating on Sabouraud agar plates; ii) evaluation of percentage of budding cells by analysis with light microscopy at $40 X$; iii) inoculation on mammalian cells monolayers VERO and MRC5 (tumoral and normal cells, respectively) grown on cover slip at $\mathrm{pH} 7$. After further 3 hours of incubation at $37^{\circ} \mathrm{C}$ the cover slips were collected, the monolayers were fixed in a solution consisting of 1 part of methanol and two parts of acetone and were stained with eosin, before microscopic examination. The budding cells were evaluated by phase-contrast light microscopy and hyphal length was measured with a reticle (also called eyepiece micrometers) measuring 100 cells for each concentration.

\section{Statistical analysis}

Data are expressed as mean \pm standard deviation (SD). Differences between groups were analyzed using the Student's t test. All data were analyzed by SPSS version 18.0 (SPSS Inc., USA), and $\mathrm{P}$ values $<0.05$ were considered to be statistically significant.

\section{Results and Discussion}

\section{Antifungal susceptibility testing}

The results obtained by antifungal susceptibility testing, carried out on non-albicans and non-Candida strains, are summarized in Table 1.

Among non-albicans strains, high fluconazole minimum inhibitory concentrations (MICs), of $316 \mu \mathrm{g} \mathrm{mL}$, were observed only in C. glabrata (1 strain resistant and 5 strains with dose-dependent susceptibility). On the other hand, all other strains showed susceptibility to almost all antifungal tested. This result is in line with other reports that found a resistance rate of $21.1 \%$ to fluconazole (4), more frequently isolated from women suffering from RVVC (18, 21). Recurrent episodes of VVC are in fact more often caused by non-albicans species, for which azole antifungal agents are less likely to be effective (21), in particular for C. glabrata (22).

\section{Non-albicans growth rate in the presence of 18-BGA}

18 - $\beta$ GA has been previously demonstrated to have inhibitory activity against C.albicans strains (4), isolated from patients with RVVC. Therefore, we tested the antifungal activity of $18-\beta \mathrm{GA}$ on C. albicans and non-albicans strains.

Table 1. Antifungal susceptibility of 24 non-albicans strains (13 Candida glabrata and 11 other species).

\begin{tabular}{|c|c|c|c|c|c|c|c|c|}
\hline & & lbicans & Id non-Can & & & Candid & abrata & \\
\hline & $\mathrm{MIC}_{50}$ & $\mathrm{MIC}_{90}$ & Range & Mean & $\mathrm{MIC}_{50}$ & $\mathrm{MIC}_{90}$ & Range & Mean \\
\hline $\mathrm{AB}$ & 0.25 & 0.5 & $0.03-05$ & 0.24 & 0.25 & 0.5 & $0.06-0.5$ & 0.25 \\
\hline FZ & 4 & 16 & $0.25-64$ & 9.01 & 8 & 16 & $0.25-64$ & 13.86 \\
\hline IZ & 0.5 & 0.5 & $0.016-4$ & 0.64 & 0.5 & 0.5 & $0.016-4$ & 0.96 \\
\hline $\mathrm{KZ}$ & 0.125 & 0.5 & $0.03-2$ & 0.27 & 0.25 & 0.5 & $0.03-2$ & 0.41 \\
\hline $\mathrm{FC}$ & $<0.03$ & 0.03 & $<0.03-0.125$ & 0.03 & 0.03 & 0.03 & 0.03 & 0.03 \\
\hline VOR & 0.03 & 0.25 & $0.008-1$ & 0.12 & 0.125 & 0.25 & $0.008-1$ & 0.19 \\
\hline
\end{tabular}

AB, amphotericin; FZ, fluconazole; IZ, itraconazole; KZ, ketoconazole; FC, 5-fluorocytosine; VOR, voriconazole. 
Figure 1A shows the growth curves obtained for 24 non-albicans strains incubated with different concentrations of 18- $\beta \mathrm{GA}$, ranging from 0.09 to $100 \mu \mathrm{g} \mathrm{mL}^{-1}$, at different $\mathrm{pH}(4.0,4.5$ and 7.0). Low $\mathrm{pH}$ values (4.0 and 4.5) were associated to a stronger inhibitory effect of $18-\beta \mathrm{GA}$ on yeasts growth than a $\mathrm{pH}$ of 7.0. These data suggest that $18-\beta \mathrm{GA}$ has an inhibitory effect also on non-albicans strains and that this activity is $\mathrm{pH}$-dependent.
Only doses ranging from 12.5 to $100 \mu \mathrm{g} \mathrm{mL}^{-1}$ of 18 - $\beta \mathrm{GA}$ had a significant inhibitory effect, while the growth kinetics observed for C. glabrata strains (Figure 1B) suggested a pH-dependent susceptibility to $18-\beta \mathrm{GA}$ treatment. Indeed, the growth of C.glabrata strains is reduced by $18-\beta \mathrm{GA}$ at concentrations ranging from 0.39 to $100 \mu \mathrm{g} \mathrm{mL}^{-1}$ at $\mathrm{pH} 4$ and at concentrations ranging from 12.5 to $100 \mu \mathrm{g} \mathrm{mL}^{-1}$ at $\mathrm{pH}$ 7. The higher susceptibility of $C$. glabrata

A
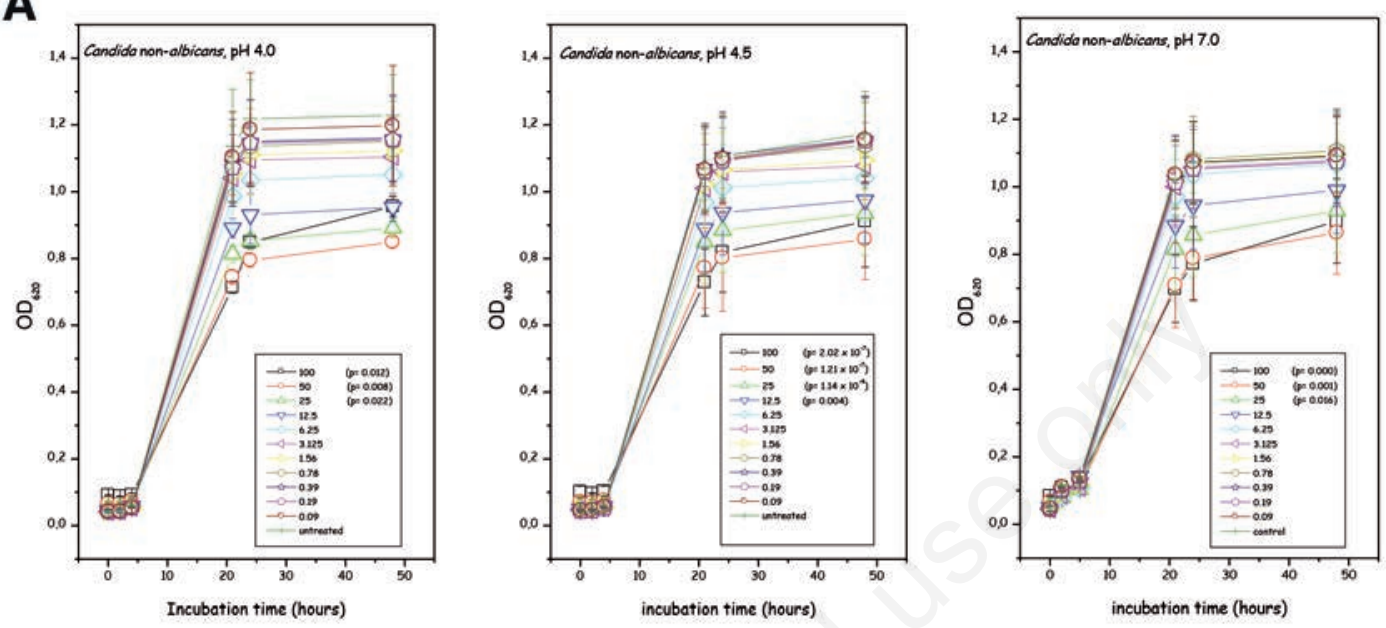

B
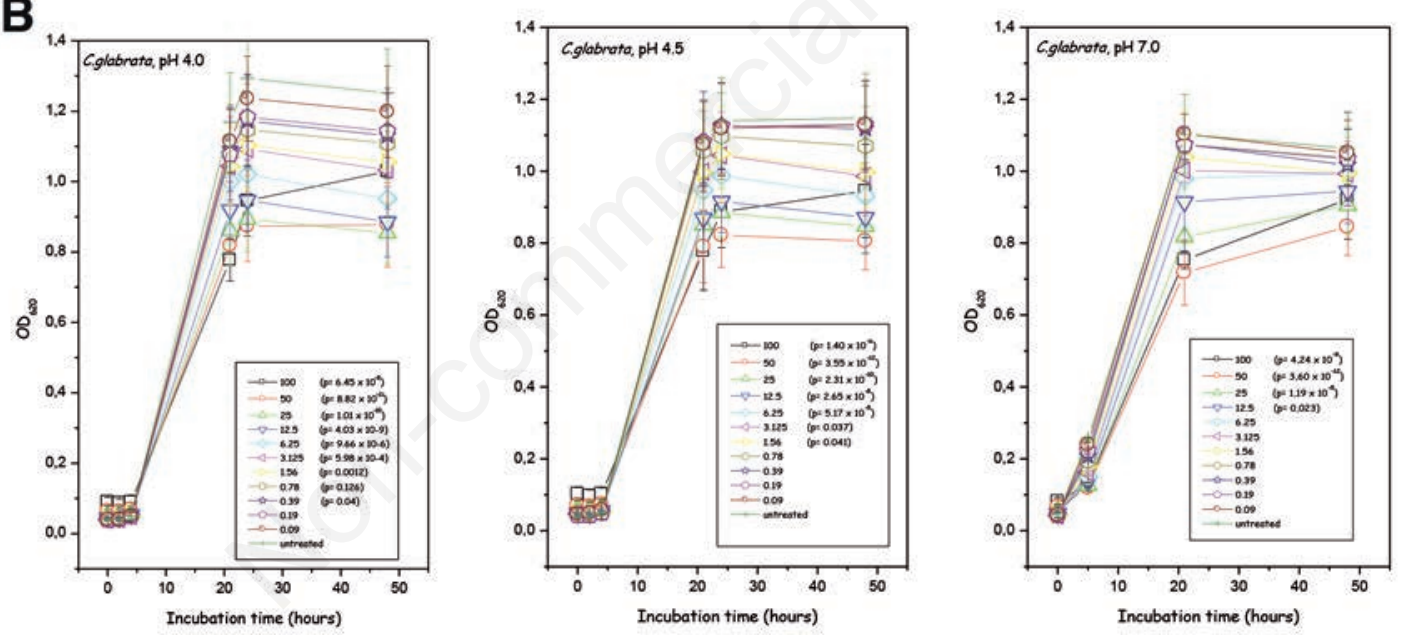

Figure. 1. Growth kinetics of (A) 24 non-albicans strains (B) 13 C. glabrata cultured at different concentrations of 18- $\beta$ GA (ranging from 0.09 to $\left.100 \mu \mathrm{g} \mathrm{m}^{-1}\right)$. Lines: $\mathrm{OD}_{620}$ mean values $\pm \mathrm{SD}$ : standard deviation.

Table 2. Growth kinetics of seven Candida albicans strains cultured at different concentration of 18- $\beta$ GA and of HA, alone and in combination. SD: standard deviation.

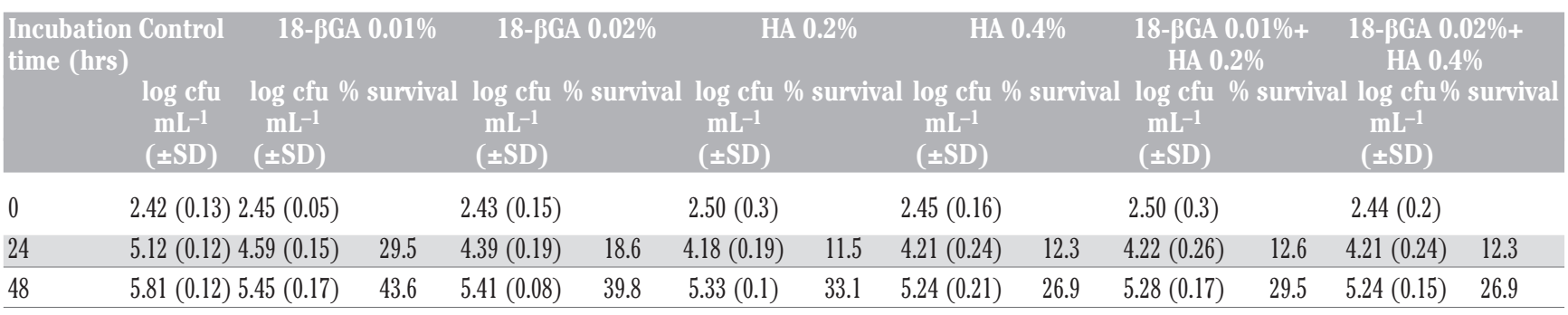


strains to $18-\beta \mathrm{GA}$ compared to the other non-albicans strains suggests that the anti-Candida activity of $18-\beta G A$ is not influenced by the susceptibility level to azole antifungal drugs.

This finding is of key importance, considering that vaginal environment has an acidic $\mathrm{pH}$.

Indeed, Candida spp. is known to cause infections in a number of host niches with markedly different $\mathrm{pH}$ levels and the ability of Candida spp. to react appropriately to different $\mathrm{pH}$ levels is crucial to its pathogenicity (8). Ambient $\mathrm{pH}$ influences several physiological functions, including morphogenesis. Under optimal temperature conditions $\left(37^{\circ} \mathrm{C}\right)$, filamentation is facilitated by near-neutral ambient $\mathrm{pH}$ values, but it is considerably reduced at $\mathrm{pH}$ values below 6; virtually only the yeast form exists at a $\mathrm{pH}$ of 4 (10).

\section{Candida albicans growth rate in the presence

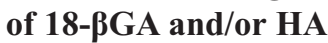

It has been proven that high molecular weight HA can inhibit the growth of $C$. albicans (23); therefore, the effect of two concentrations of $18-\beta \mathrm{GA}$ and HA, both alone and in combination, were tested on the growth of seven $C$. albicans strains. The results obtained are reported in Table 2.

The anti-Candida activity of both compounds was confirmed, with a survival rates ranging from $11.5 \%$ to $29.5 \%$ and from $26.9 \%$ to $43.6 \%$ after 24 and 48 hours of incubation, respectively. In all tests the reduction of growth compared to controls was statistically significant $(\mathrm{P}<0.0001)$.

Candida albicans is a dimorphic fungus capable of converting itself between yeast and hyphal forms (26), the former associated with commensal carriage, the latter with disease (10). There is indeed evidence of mutant forms of $C$. albicans that were locked into the yeast form, and were avirulent $(10,24)$. It has been demonstrated that elongated hyphae evade phagocitic cells, thus representing a pathogenic factor $(5,14)$. Therefore, the ability of 18 $\beta G A$ and HA, both alone and in combination, to inhibit or reduce the bud formation in RPMI 1640 broth was tested, and the hyphal elongation on $C$. albicans plated on mammalian cells monolayer after treatment with the two drugs, was measured. The results obtained after two hours of incubation (Figure 2) showed a significant reduction of budding cells (BCs).

In fact, no BCs were detectable in presence of $18-\beta \mathrm{GA}$ plus $\mathrm{HA}$, and a $3.4 \%$ of $\mathrm{BCs}$ were detected after incubation in $18-\beta \mathrm{GA}$ (concentration of $0.01 \%$ ) against a $7.2 \%$ of control BCs. These differences remained statistically significant also after 24 hours of incubation (Figure 2). These data are in agreement with the amount of growth reduction observed in the survival kinetics.

The incubation for 24 and $48 \mathrm{~h}$ in RPMI 1640 broth of C. albi- cans cells, before plating on mammalian cells monolayer (VERO and MRC5), with 18- $\beta$ GA and HA, both alone and in combination, was associated with a significant reduction of the germ tube elongation $(\mathrm{P}<0.0001)$. After $24 \mathrm{~h}$ of incubation in RPMI 1640 broth, and subsequent three hours of incubation of yeasts on VERO mammalian cells monolayer, the reduction rate ranged from $27.9 \%$ to $63.6 \%$. The same procedure on MRC5 mammalian cells monolayer, produced a reduction rate ranging from $17.9 \% 31.3 \%$ to $84.8 \%$ $57.3 \%$. Similarly, after 48 h of incubation in RPMI 1640 broth, and subsequent three hours of incubation of yeasts on VERO mam-

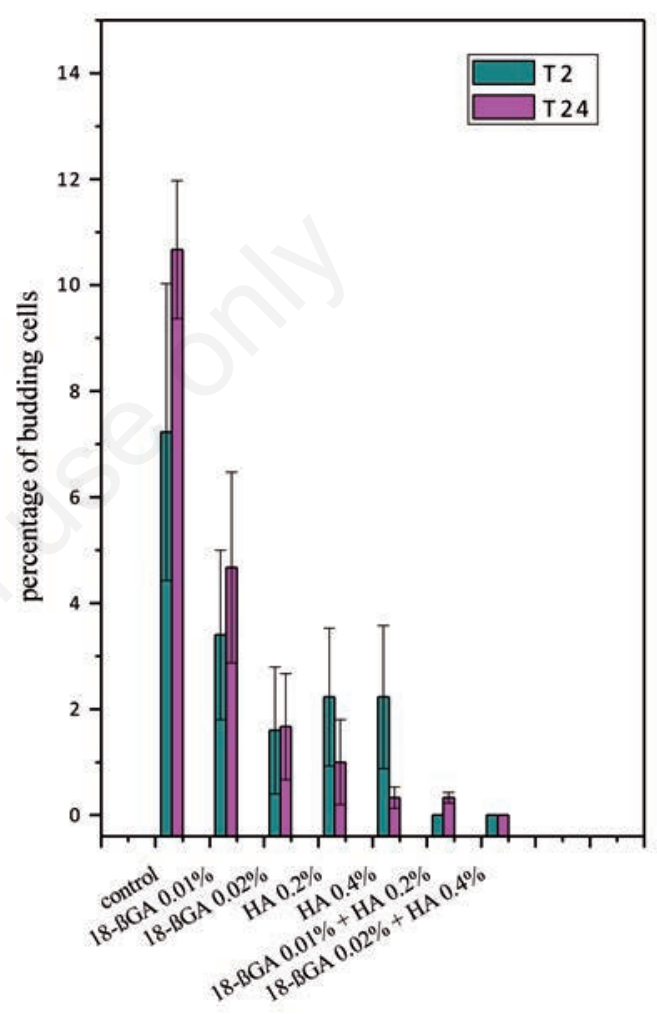

Figure 2. Budding cells of three Candida albicans strains incubated, for 2 and 24 hours, in the presence of different concentrations of 18- $\beta \mathrm{GA}$ and of HA alone and in combination. The bars represent standard deviation

Table 3. Effect on Candida albicans cells germ tube elongation after incubation for 24 and 48 hours in RPMI 1640 broth containing

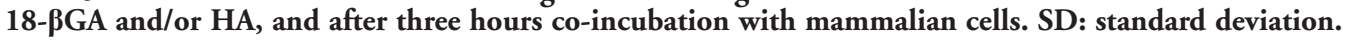

\begin{tabular}{|c|c|c|c|c|c|c|c|c|}
\hline Treatment & $\begin{array}{r}\text { VER } \\
24 \\
\mu \mathrm{m}( \pm \mathrm{SD})\end{array}$ & $\begin{array}{l}\text { cells, germ } \\
\text { reduction }\end{array}$ & $\begin{array}{l}\text { ative tube } 1 \\
\mu \mathrm{m}( \pm \mathrm{SD})\end{array}$ & $\begin{array}{l}\text { ength } \\
8 \mathrm{~h} \\
\% \text { reduction }\end{array}$ & $\begin{array}{r}\text { MRR } \\
24 \\
\mu \mathrm{m}( \pm \mathrm{SD})\end{array}$ & $\begin{array}{l}5 \text { cells, germ } \\
\text { h reduction }\end{array}$ & $\begin{array}{r}4 \\
\text { tive tube le } \\
\mu \mathrm{m}( \pm \mathrm{SD})\end{array}$ & $\begin{array}{l}\text { igth } \\
\% \text { h } \\
\% \text { reduction }\end{array}$ \\
\hline Untreated & $42.65(12.5)$ & & $48.78(6.2)$ & & $54.20(9.8)$ & & $56.38(10.1)$ & \\
\hline $18-\beta \mathrm{GA} 0.01 \%$ & $30.75(7.9)$ & 27.90 & $33.50(6.5)$ & 31.32 & $44.50(5.19)$ & 17.90 & $39.00(8.66)$ & 30.83 \\
\hline $18-\beta \mathrm{GA} 0.02 \%$ & $25.44(9.5)$ & 40.35 & $26.93(7.5)$ & 44.79 & $39.30(5.60)$ & 27.49 & $34.63(9.80)$ & 38.58 \\
\hline HA $0.2 \%$ & $27.15(10)$ & 36.34 & $32.18(9.6)$ & 34.03 & $35.20(6.59)$ & 35.06 & $34.69(9.81)$ & 38.39 \\
\hline HA $0.4 \%$ & $23.25(11.5)$ & 45.48 & $27.56(7.8)$ & 43.50 & $31.60(6.83)$ & 41.70 & $31.00(8.71)$ & 45.02 \\
\hline $18-\beta \mathrm{GA} 0.01 \%+$ HA $0.2 \%$ & $19.43(9.3)$ & 54.44 & $24.81(9.1)$ & 49.14 & $21.10(8.64)$ & 61.07 & $21.69(7.85)$ & 61.53 \\
\hline $18-\beta \mathrm{GA} 0.02 \%+$ HA $0.4 \%$ & $15.5(11.3)$ & 63.65 & $20.81(7.6)$ & 57.34 & $8.19(4.57)$ & 84.89 & $17.44(5.20)$ & 69.07 \\
\hline
\end{tabular}


malian cells monolayer, the reduction rate ranged from $31.3 \%$ $17.9 \%$ to $57.3 \%$. Likewise, for MRC5 cells reduction rate ranged from $30.8 \%$ to $69.1 \%$ (Table 3 ).

In particular, the combination of $18-\beta \mathrm{GA}$ plus HA decreased germ tube elongation of more than $49.1 \%$, compared to that obtained with single drug, ranging from $17.9 \%$ to $45.5 \%$.

The limitations of this study are represented by the relatively low number of strains evaluated, and the lack of confirmation of the results in animal models. These issues will be addressed by future studies.

\section{Conclusions}

In this study we evaluated in vitro the (anti-yeasts) antiCandida activity of 18ß-GA and HA, alone and in combination, in the light of their possible use as topical treatment for acute VVC. The main results are that $18 \beta-\mathrm{GA}$ and HA anti-Candida activity seems independent from antifungal susceptibility, that the growth inhibition seems stronger at acidic $\mathrm{pH}$, and that they reduce both budding cells formation and germ tube elongation on mammalian cell monolayers. Those findings highlight how 18 - $\beta$ GA and HA could be considered a possible alternative to azole antifungal agents for the topical treatment of VVC and RVVC.

\section{References}

1. Achkar JM, Fries BC. Candida infections of the genitourinary tract. Clin Microbiol Rev 2010;23:253-73.

2. Anderson MR, Klink K, Cohrssen A. Evaluation of vaginal complaints. JAMA 2004;291:1368-79.

3. Ardizzoni A, Neglia RG, Baschieri MC, et al. Influence of hyaluronic acid on bacterial and fungal species, including clinically relevant opportunistic pathogens. J Mater Sci Mater Med 2011;22 2329-38.

4. Bauters TG, Dhont MA, Temmerman MI, Nelis HJ. Prevalence of vulvovaginal candidiasis and susceptibility to fluconazole in women. Am J Obstet Gynecol 2002;187:569-74.

5. Berman J. Morphogenesis and cell cycle progression in Candida albicans. Curr Opin Microbiol 2006;9:595-601.

6. Carlson GA, Dragoo JL, Samimi B, et al. Bacteriostatic properties of biomatrices against common orthopaedic pathogens. Biochem Biophys Res Commun 2004;321:472-8.

7. Fiore C, Eisenhut M, Krausse R, et al. Antiviral effects of Glycyrrhiza species. Phytother Res 2008;22:141-8.

8. Fonzi WA. Role of $\mathrm{pH}$ response in Candida albicans virulence. Mycoses 2002;45:16-21.
9. Fukai T, Marumo A, Kaitou K, et al. Antimicrobial activity of licorice flavonoids against methicillin-resistant Staphylococcus aureus. Fitoterapia 2002;73:536-9.

10. Hammer KA, Carson CF, Riley TV. Melaleuca alternifolia (tea tree) oil inhibits germ tube formation by Candida albicans. Med Mycol 2000;38:355-62.

11. Kang JH, Kim YY, Chang JY, Kho HS. Influences of hyaluronic acid on the anticandidal activities of lysozyme and the peroxidise system. Oral Dis 2011;17:577-83.

12. Kennedy MA, Sobel JD. Vulvovaginal candidiasis caused by non-albicans Candida Species: new insights. Curr Infect Dis Rep 2010;12:465-70.

13. Kim HK, Park Y, Kim HN, et al. Antimicrobial mechanism of $\beta$-glycyrrhetinic acid isolated from licorice, Glycyrrhiza glabra. Biotech Lett 2002;24:1899-902.

14. Lo HJ, Köhler JR, Di Domenico B, et al. Nonfilamentous C.albicans mutants are avirulent. Cell 1997;90:939-49.

15. Matsumoto T, Takahashi T, Yamada H. A novel approach for screening of new anti-Helicobacter pylori substances. Biol Pharm Bull 2008;31:143-5.

16. Mendling W. Guideline: Vulvovaginal candidosis (AWMF 015/072), S2k (excluding chronic mucocutaneous candidosis). Mycoses 2015;58:1-15.

17. Motzei LM, Lindsey KL, van Staden J, Jäger AK. Screening of traditionally used South African plants for antifungal activity against Candida albicans. J Ethnopharmacol 2003;86:235-41.

18. National Committee for Clinical Laboratory Standards. 2002. Reference Method for Broth Dilution Antifungal Susceptibility Testing of Yeast. Approved standard, 2nd edn. NCCLS document M27-A2. 22 no 15. NCCLS: Wayne, PA

19. Pellati D, Fiore C, Armanini D, et al. In vitro effects of glycyrrhetinic acid on the growth of clinical isolates of Candida albicans. Phytother Res 2009;23:572-4.

20. Pirnazar P, Wolinsky L, Nachnani S, et al. Bacteriostatic effects of hyaluronic acid. J Periodontol 1999;70:370-4.

21. Richter SS, Galask RP, Messer SA, et al. Antifungal susceptibilities of Candida species causing vulvovaginitis and epidemiology of recurrent cases. J Clin Microbiol 2005;43:2155-62.

22. Rodrigues CF, Silva S, Henriques M. Candida glabrata: a review of its features and resistence. Eur J Clin Microbiol Infect Dis 2014;33:673-88.

23. Sakai A, Akifusa S, Itano N, et al. Potential role of high molecular weight hyaluronan in the anti-Candida activity of human oral epithelial cells. Med Mycol 2007;45:73-9.

24. Sobel JD. Vulvovaginal candidosis. Lancet 2007;369:1961-71.

25. Sobel JD, Faro S, Force RW, et al. Vulvovaginal candidiasis: epidemiologic, diagnostic, and therapeutic considerations. Am J Obstet Gynecol 1998;178:203-11.

26. Whiteway M, Bachewich C. Morphogenesis in Candida albicans. Ann Rev Microbiol 2007;61:529-53. 